Research Article

\title{
Kinetic Studies of the Glycerolysis of Urea to Glycerol Carbonate in the Presence of Amberlyst-15 as Catalyst
}

\author{
Hary Sulistyo1,*), Wahyudi Budi Sediawan¹, Reviana Inda Dewi Suyatmo², Indah Hartati1,3 \\ ${ }^{1}$ Department of Chemical Engineering, Faculty of Engineering, Universitas Gadjah Mada, 55281, \\ Indonesia. \\ ${ }_{2}^{2}$ Department of Polymer Chemical Engineering, Politeknik STMI, 10510, Indonesia. \\ ${ }^{3}$ Department of Chemical Engineering, Faculty of Engineering, Universitas Wahid Hasyim, 50232, \\ Indonesia.
}

Received: $8^{\text {th }}$ September 2020; Revised: $19^{\text {th }}$ January 2021; Accepted: 20th January 2021

Available online: 29th January 2021; Published regularly: March 2021

\section{Abstract}

Amberlyst-15, a strong acidic ion-exchange resin, has showed as a potential and an effective catalyst for the glycerolysis process of urea to glycerol carbonate. In this work, the kinetic model of the urea glycerolysis over Amberlyst-15 catalyst was investigated. The kinetic model was developed by considering simultaneous steps of urea dissolution in glycerol, mass transfer of urea and glycerol from the bulk of the liquid into the outer part of the catalyst, diffusion of urea and glycerol into the inner part of the particle through the catalyst pores, and irreversible second order reaction of urea and glycerol on the active sites. The irreversibility of second order reaction of urea glycerolysis was validated and proven. The proposed kinetic model was simulated and validated with the experimental data. The kinetic studies show that mechanism proposed works well. Furthermore, the activation energy was found to be $145.58 \mathrm{~kJ} \cdot \mathrm{mol}^{-1}$ and the collision factor was in $8.00 \times 10^{10}\left(\mathrm{~m}^{3}\right)^{2} \cdot \mathrm{kg}^{-1} \cdot \mathrm{mol}^{-1} \cdot \mathrm{s}^{-1}$. The simulation result shows that the predicted liquid temperatures were close to the experimental temperature data. It also gave glycerol concentration profile inside the catalyst particle as a function of glycerolysis time and position.

Copyright (C) 2021 by Authors, Published by BCREC Group. This is an open access article under the CC BY-SA License (https://creativecommons.org/licenses/by-sa/4.0).

Keywords: Amberlyst-15; Glycerolysis; Glycerol carbonate; Kinetics; Urea

How to Cite: H. Sulistyo, W.B. Sediawan, R.I.D. Suyatmo, I. Hartati (2021). Kinetic Studies of the Glycerolysis of Urea to Glycerol Carbonate in the Presence of Amberlyst-15 as Catalyst. Bulletin of Chemical Reaction Engineering \& Catalysis, 16(1), 52-62 (doi: 10.9767/bcrec.16.1.8893.52-62)

Permalink/DOI: https://doi.org/10.9767/bcrec.16.1.8893.52-62

\section{Introduction}

Biodiesel production and consumption as alternative fuel have increased due to various advantages such as being ecofriendly, renewable, biodegradable and having high boiling point in which make it as one of the safest and non-toxic fuel option. Biodiesel global production is projected to reach almost 10.3 billion gallons by 2024 [1] with Germany, Brazil and Argentina as

* Corresponding Author.

Email: hary@ugm.ac.id (H. Sulistyo); the top three biodiesel producer [2]. The increasing trend of biodiesel production is followed up with the one of glycerol as the main sideproduct of biodiesel industry. Kong et al. [1] mentioned that glycerol covers $10 \mathrm{wt} \%$ of the total biodiesel production and that glycerol valorization into various valuable chemicals may increase the viability of biodiesel industry $[1,3]$. Syngas, hydrogen, solketal, polyhydroxylalkanoates, glycidol, and glycerol carbonate are some of fuels and chemicals derived from gycerol $[1,4-8]$. 
Glycerol carbonate is gaining both industrial and scientific attention due to its remarkable physical and chemical properties in which lead to its wide range applications. Glycerol carbonate is directly utilized as general purpose solvent, electrolyte liquid carrier for batteries, biomedical precursor, blowing agent, wetting agent, plant vitalizer, membrane coating in gas separation processes, and curing agent in cement and concrete industry [7,9-12]. Meanwhile, surfactants, polymers, and chemical intermediates are examples of indirect application of glycerol carbonate.

Glycerol carbonate can be synthesized through direct and indirect routes. Carboxylation of gycerol with $\mathrm{CO}_{2}$ and oxidative carboxylation of glycerol with $\mathrm{CO}$ and $\mathrm{O}_{2}$ are the two direct synthesis routes of glycerol carbonate. Meanwhile the indirect synthesis routes of glycerol carbonate from glycerol are comprise of phosgenation, urea glycerolys, as well as alkyl carbonate and dialkyl carbonate transesterification [13].

Urea is considered as an alternative route for glycerol carbonate synthesis due to several reasons such as its affordability, easily available and replaces the current GC synthesis method in which using toxic compound such as phosgene. It is approximately $10^{8}$ tons of urea is produced annually worldwide [14]. Fernandes and Yadav [3] stated that the attractiveness of the glycerolysis of urea to glycerol carbonate route is mainly due to the absence of solvent and that the process is simple and results in high selectivity and yields.

Glycerolysis of urea to glycerol carbonate was conducted in the presence of homogeneous or heterogeneous catalyst. The application of homogeneous catalysts, such as: zinc sulfate, ionic liquid, lanthanum(III) chloride, and magnesium sulfate are causing additional costs towards catalyst recovery and product purification $[14,15]$. Recently, the applications of heterogeneous catalyst in glycerol carbonate production process have been respectively investigated for this reaction due to its better separation and its ability to be reuse. Lanthanum oxide, polymer-supported metal containing ionic liquid catalyst, $\gamma$-zirconium phosphate, calcined manganese sulfate, ion exchange, gypsum and gold based catalyst are examples of heterogeneous catalyst studied [10,14]. Urea glycerolysis using $\mathrm{MgO}, \mathrm{CaO}$, and mixed oxide have attained glycerol conversion up to $71 \%$ at lower temperature and lower catalyst concentration [3].

Most of researchers in glycerolysis of urea for glycerol carbonate production studied the operating condition to get a higher glycerol conversion and focused on kinetics studies of urea glycerolysis reaction. Lertlukkanasuk et al. [15] derived the kinetics model and determined the kinetics rate constant by assuming the pseudo-homogeneous model. Two steps reaction mechanism were developed by Kim et al. [12]. Fernandes and Yadav [3] developed a kinetics model on glycerol carbonate formation using Magnesium Oxide as catalyst in which the Langmuir Hinshelwood Hougen Watson (LHHW) model was used with surface active as basic and acidic sites on the catalyst surface for adsorption of glycerol and urea. Sulistyo et al. [16] investigated the reaction rate mechanism for heterogeneous catalytic reaction of glycerol carbonate synthesis from glycerol and urea in the presence of amberlyst- 15 as a catalyst. The proposed kinetics model was developed and validated by assuming that the elementary steps was based on the Langmuir-Hinshelwood (LH) mechanism [16]. There have been limited studies concerned on the development of kinetics studies based on assumption of that urea glyceroysis occurs by simultaneous step of mass transfer, diffusion and reaction in the surface active catalyst. Therefore, the present study was aimed to derive the kinetic model of the glycerol carbonate synthesis from glycerol and urea over Amberlyst-15 catalyst by considering simultaneous step of mass transfer, diffusion and reaction in the surface active catalyst.

\section{Materials, Modelling, and Methods}

\subsection{Materials}

Glycerol with $95.78 \%$ purity was purchased from Sigma Aldrich. Urea with a purity of 98.57\% was produced and suplied by PUSRI, an Indonesian fertilizer plant. Amberlyst-15 resin, the catalyst used in this research, was purchased from Sigma Aldrich with CAS number 39389-20-3. Urea glycerolysis were performed in three-neck flask equipped with heating mantle, thermometer, stirrer and condenser.

\subsection{Synthesis of Glycerol Carbonate}

Firstly, glycerol was inserted to the threeneck flask as reactor, then heated to reach 80 ${ }^{\circ} \mathrm{C}$. Urea and Amberlyst-15 (2-4\%) as catalyst were loaded into the reactor. The reactor temperatures were recorded every 15 minutes until the reactor temperature reach of $120{ }^{\circ} \mathrm{C}$ while the agitation speed was set of $375 \mathrm{rpm}$. The samples were taken every 1 hour for 5 hours of experiment. The amount of glycerol 
was analyzed using periodic acid based on iodometric titration method according to AOCS Official Method Ca 14-56.

\subsection{Glycerol Conversion}

The glycerol conversion was calculated by assuming that all of glycerol was converted into glycerol carbonate. This assumption was taken by considering the high selectivity of urea glycerolysis reported in several literatures [3,12]. Conversion and and glycerol carbonate selectivity as high as $70 \%$ and $100 \%$ were obtained from urea glycerolysis in the presence magnesium oxide [3]. Meanwhile, Aresta et al. [12] reported conversion and selectivity as high as $80 \%$ and $100 \%$, respectively, on urea glycerolysis over $\gamma$-zirconium phosphate catalyst. The glycerol conversion was calculated as follows:

$$
X_{A}=\frac{C_{A 0}-C_{A}}{C_{A 0}} \times 100 \%
$$

\subsection{Proposed Kinetics Model}

The reaction rate for heterogeneous fluid solid catalytic reaction has been described by several models, such as: Pseudo Homogeneous (PH), Eley Rideal (ER), Langmuir Hinshelwood Hougen Watson (LHHW) models. The simplest model is pseudo homogeneous model in which applied in the kinetics studies of glycerol carbonate synthesis from glycerol and dimethyl carbonate over DBU catalyst [17]. In case of urea gycerolysis, several researchers have been reporting various kinetics models which represent the kinetics of urea glycerolysis $[3,15]$. Fernandes and Yadav [3] confirmed a zero order kinetics and Langmuir-HinshelwoodHougen-Watson model for the adsorption step of urea glycerolysis using magnesium oxide as catalyst. Lertlukkanasuk et al. [15] studied the reactive distillation of urea glycerolysis in the presence of $\mathrm{Co}_{3} \mathrm{O}_{4} / \mathrm{ZnO}$ catalyst and proposed a kinetics model based on reversible reaction of urea and glycerol. Sulistyo et al. [16] developed a kinetics model based on elementary steps based on the Langmuir-Hinshelwood in urea glycerolysis over Amberlist-15 catalyst.

In this work, the kinetics model for synthesis of glycerol carbonate from glycerol and urea using Amberlyst-15 as a porous catalyst is developed by considering simultaneous steps of: (i). urea (B) dissolution in glycerol (A); (ii). mass transfer of urea and glycerol from the bulk of the liquid into the outer part of the catalyst; (iii). diffusion of urea and glycerol into the inner part of the particle through the catalyst pores; and (iv). irreversible second order reaction of urea and glycerol on the active sites of catalyst pores. Urea dissolves quickly, so the first step can be ignored.

Mass balance of glycerol in bulk fluid is as follows:

$$
V \frac{d C_{A_{L}}}{d t}=-4 \pi R_{k}^{2} k_{c_{A}} N_{k}\left(C_{A_{L}}-\left.C_{A}^{\prime}\right|_{R_{k}}\right)
$$

with the initial condition of:

$$
\text { IC : } t=0, C_{A L}=C_{A 0}
$$

Mass balance of urea (B) in bulk of the fluid gives:

$$
V \frac{d C_{B_{L}}}{d t}=-4 \pi R_{k}^{2} k_{c_{B}}^{\prime} N_{k}\left(C_{B_{L}}-\left.C_{B}^{\prime}\right|_{R_{k}}\right)
$$

where the initial condition for Equation (3) is as follows:

IC : $t=0, C_{B L}=C_{B 0}$

Mass balance of $\mathrm{A}$ in the volume element of spherical catalyst is:

$$
\begin{aligned}
\frac{\partial^{2} C_{A}^{\prime}}{\partial r^{2}} & +\frac{2}{r} \frac{\partial C_{A}^{\prime}}{\partial r}-\frac{\rho_{k} C_{A}^{\prime} C_{B}^{\prime}}{D_{e_{A}}} A_{r} \exp \left(-\frac{E}{R T}\right) \\
& =\frac{\phi_{p}}{D_{e_{A}}} \frac{\partial C_{A}^{\prime}}{\partial t}
\end{aligned}
$$

where the initial condition and the boundary condition for Equation (4) are as follow:

$$
\begin{aligned}
& \mathrm{IC}: t=0 ; C_{A}^{\prime}=0 ; T=T_{0} \\
& \mathrm{BC}: r=0 ; \frac{\partial C_{A}^{\prime}}{\partial r}=0 \text { and } \\
& \quad r=R_{k} ; D_{e_{A}} \frac{\partial C_{A}^{\prime}}{\partial r}=k_{C_{A}}\left(C_{A_{L}}-\left.C_{A}^{\prime}\right|_{R_{k}}\right)
\end{aligned}
$$

Mass balance of B in the volume element of spherical catalyst is given by Equation (5).

$$
\begin{aligned}
\frac{\partial^{2} C_{B}^{\prime}}{\partial r^{2}} & +\frac{2}{r} \frac{\partial C_{B}^{\prime}}{\partial r}-\frac{\rho_{k} C_{A}^{\prime} C_{B}^{\prime}}{D_{e_{B}}} A_{r} \exp \left(-\frac{E}{R T}\right) \\
& =\frac{\phi_{p}}{D_{e_{B}}} \frac{\partial C_{B}^{\prime}}{\partial t}
\end{aligned}
$$

Meanwhile, the initial condition and the boundary condition are:

$$
\begin{aligned}
& \mathrm{IC}: t=0 ; C_{B}^{\prime}=0 ; T=T_{0} \\
& \mathrm{BC}: r=0 ; \frac{\partial C_{B}^{\prime}}{\partial r}=0 \quad \text { and } \\
& r=R_{k} ; D_{e B} \frac{\partial C_{B}^{\prime}}{\partial r}=k_{c_{B}}\left(C_{B_{L}}-\left.C_{B}^{\prime}\right|_{R_{k}}\right)
\end{aligned}
$$




\subsection{Numerical Analysis}

There are four parameters in Equations (25) need to be calculated including mass transfer coefficient, diffusivity, and reaction rate constant which consist of $A_{r}$ (frequency factor) and $E$ (activation energy). The mass transfer coefficient was correlated with Sherwood number $(S h)$ (Equation (6)). The catalyst diameter is small enough $\left(R_{k}=8.5 \times 10^{-4} \mathrm{~m}\right)$, hence it was assumed that catalyst was in stagnant liquid.

$$
S h=\frac{k_{c} d_{p}}{D_{A B}}=2
$$

The diffusivity can be calculated by applied Wilke-Chang equation (Equation (7)) as follows:

$$
D_{A B}\left(m^{2} / s\right)=\frac{117.3 \times 10^{-18}\left(\varphi M_{B}\right)^{0.5} T}{\mu v_{A}^{0.6}}
$$

According to Fogler [18] the effective diffusivity in pore of catalyst can be estimated by applied:

$$
D_{e}=\frac{D_{A B} \Phi_{p} \sigma}{\tau}
$$

Nonetheless, both tortuosity and constriction factor tortuosity are difficult to be estimated, hence in this work, the effective diffusivity was estimated by applying Equation (9).

$$
D_{e}=D_{A B} \Phi_{p}
$$

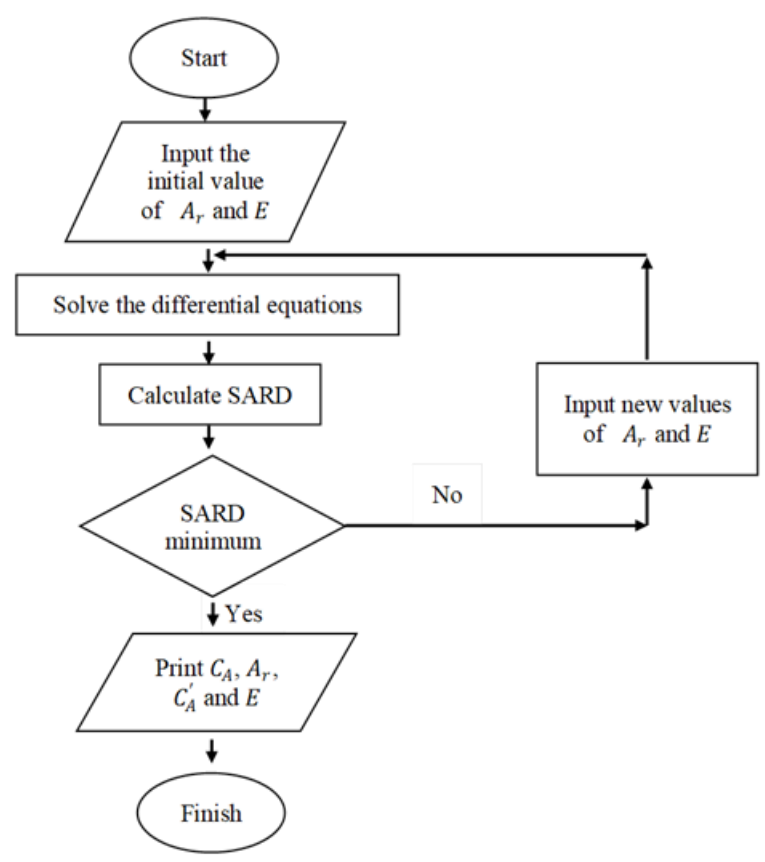

Figure 1. The Algorithm for calculation of kinetics model parameters $A_{r}$ and $E$.
The next two parameters $A_{r}$ (frequency factor) and $E$ (activation energy) were then calculated by optimization of Equations (2) to (5). Equations (2-5) were numerically solved by applied method of lines in which then Matlab program was used to perform the calculation according to the algorithm as depicted on Figure 1. The kinetics model was validated by using the obtained experimental data of glycerol concentration. Values of $A_{r}$ (frequency factor) and $E$ (activation energy) were evaluated by minimising the Sum of Absolute Relative Difference (SARD) (Equation (10)).

$$
S A R D=\sum\left|\frac{C_{A_{L_{\text {calc }}}}-C_{A_{L_{\text {data }}}}}{C_{A_{L_{\text {data }}}}}\right|
$$

\section{Results and Discussions}

\subsection{Reaction Temperature Profile}

The urea loading in glycerol carbonate production results in system temperature decreasing. The system temperature will then rise until approach the setting point temperature. The equation that represents the reaction temperature changes can be approximated by Equation (11).

$$
T=a\left(1-\exp ^{-b t}\right)+c
$$

The temperature profile of empirical approach and experimental data of the urea glycerolysis performed by adding an equimolar of urea and glycerol in which reacted in the presence of $2 \%$ of Amberlyst-15, at agitation speed of $375 \mathrm{rpm}$, reaction temperature set of $120^{\circ} \mathrm{C}$ and reaction duration of 5 hours was depicted on Figure 2. It was found that the constants for

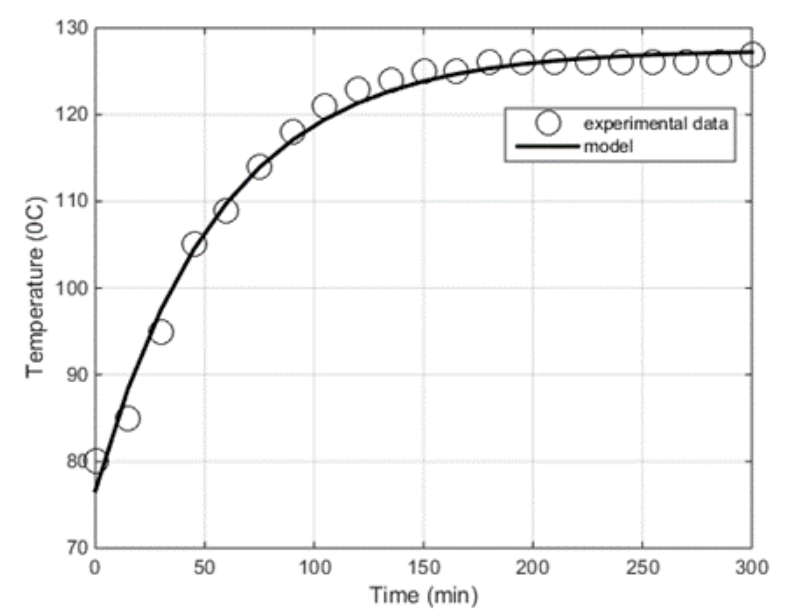

Figure 2. Empirical approach of the reaction temperature. 
Equation (10) were $a=50.81, b=0.017$, and $c$ $=76.65$.

\subsection{Irreversible Reaction Approach}

The irreversibility of the urea glycerolysis was validated by approximated the equilibrium conversion and linked with the glycerol conversion. Firstly, the glycerol conversion and reaction time was correlated for irreversible second order reaction (Equation (12)).

$$
-\frac{d C_{A}}{d t}=k C_{A}^{2}
$$

After rearrangement and integration of Equation (12) with initial condition of $t=0, x=0$, Equation (13) is obtained in which valid only for $\mathrm{t}>0$.

$$
\frac{1}{x}=a_{0}+a_{1}\left(\frac{1}{t}\right)
$$

Furthermore, based on Equation 13, we can sketch graph of conversion $(1 / x)$ versus $1 / t$, wherein for a large $t$ and close to infinite the curve is linear and the intercept is equilibrium conversion. An equimolar of urea and glycerol was reacted in the presence of $4 \%$ of Amberlyst15 . The reaction temperature was set of $120^{\circ} \mathrm{C}$ and the agitation speed was of $375 \mathrm{rpm}$. The urea glycerolysis conversion was analyzed and illustrated on Figure 3. It shows that when the reaction time is approaching infinity, equilibri-

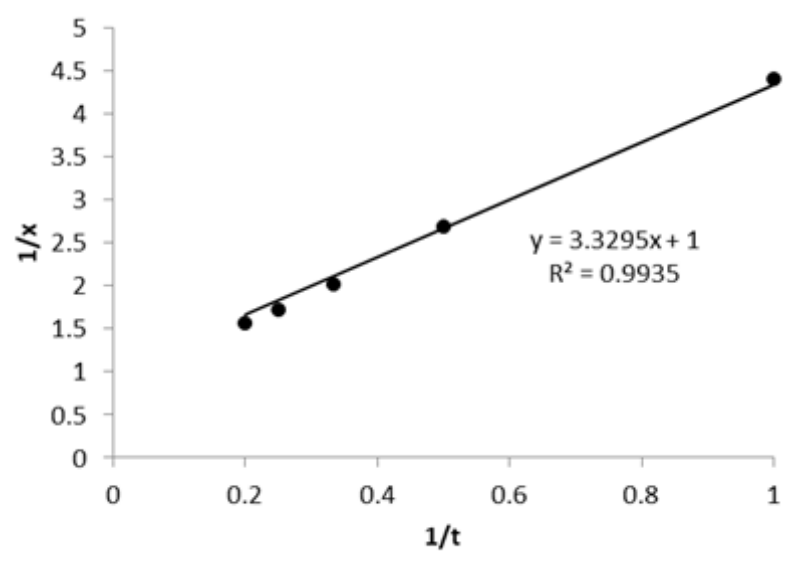

Figure 3. Glycerol conversion as function of time. um conversion is approximately of $99 \%$ while the experimental conversion is only $58.49 \%$. It means that the experimental conversion still far from the equilibrium conversion. Therefore, the proposed simplification of urea glycerolysis irreversibility is conceivable.

Glycerol carbonate and ammonia are two chemicals produced from the glycerolysis of urea. In case of urea glycerolysis carried out at $120{ }^{\circ} \mathrm{C}$, the ammonia at $120^{\circ} \mathrm{C}$ is believed in the form of vapor and since the solubility of ammonia in the liquid reacting system is very low, hence the reverse reaction of ammonia and glycerol carbonate would not be exists and can be neglected. The low solubility of ammonia in urea, glycerol carbonate and glycerol can be estimated from their Hansen solubility parameter. Sonnati et al. [10] stated that cohesive energy calculation based solubility parameter such as Hildebrand and Hansen are allowing the quantification of the solubility between chemicals. The more similar the value of solubility parameter of the chemicals, the more soluble of those chemicals in one and another $[19,20]$. The Hansen solubility parameter is comprised of dispersive, polar and $\mathrm{H}$-bonding values in which the values of the three type of Hansen solubility parameter of urea, glycerol, glycerol carbonate and ammonia were tabulated on Table 1.

Van Krevelen and Hoftyzer used the $\Delta \delta$ factor (Equation (14)) to determine the miscibility of compounds and suggested that good miscibility will be achieved if $\Delta \delta \leq 5\left(\mathrm{MPa}^{1 / 2}\right)$ [19,21]. The values of $\Delta \delta$ were calculated in respect to ammonia and tabulated on Table 1 . Table 1 showed that the values of $\Delta \delta$ are all $\geq 5$ $\left(\mathrm{MPa}^{1 / 2}\right)$. It indicates that ammonia is immiscible in urea, glycerol and glycerol carbonate.

$$
\Delta \delta=\left[\left(\delta_{D 2}-\delta_{D 1}\right)^{2}+\left(\delta_{P 2}-\delta_{P 2}\right)^{2}+\left(\delta_{H 2}-\delta_{H 1}\right)\right]^{0.5}
$$

Furthermore, the irreversibility of the urea glycerolysis was also supported by $\mathrm{Li}$ and Wang [22], who investigated the chemical equilibrium of glycerol carbonate synthesis from glycerol with dimethyl carbonate, ethylene car-

\begin{tabular}{|c|c|c|c|c|c|}
\hline \multirow{2}{*}{ Chemical } & \multicolumn{3}{|c|}{ Hansen solubility parameter, $\left(\mathrm{MPa}^{1 / 2}\right)$} & \multirow{2}{*}{$\begin{array}{c}\Delta \delta \\
\left(\mathrm{MPa}^{1 / 2}\right)\end{array}$} & \multirow{2}{*}{ Ref } \\
\hline & $\delta_{D}$ & $\delta_{P}$ & $\delta_{H}$ & & \\
\hline Urea & 22.9 & 14.9 & 21.3 & 9.87 & {$[19]$} \\
\hline Glycerol & 17.4 & 12.1 & 29.3 & 12.6 & {$[10]$} \\
\hline Glycerol carbonate & 17.9 & 19.5 & 21.5 & 6.76 & {$[10]$} \\
\hline Ammonia & 13.7 & 15.7 & 17.8 & N/A & - \\
\hline
\end{tabular}
bonate, carbon dioxide and urea. It was found

Table 1. Hansen solubility parameter of urea, glycerol, glycerol carbonate and ammonia. 
that the equilibrium constant of urea glycerolysis performed at pressure of $10 \mathrm{~Pa}$ and at temperature of $298.15 \mathrm{~K}$ to $453.15 \mathrm{~K}$ was $0.516 \times 10^{2}$ $-7.670 \times 10^{8}$, respectively [22]. The high equilibrium constant indicates the irreversibility of urea glycerolysis reaction.

\subsection{Kinetics Modeling Result}

To prove the suitability of the proposed mathematical model, series of urea glycerolysis experiments were conducted at temperature from $80{ }^{\circ} \mathrm{C}$ to $120^{\circ} \mathrm{C}$, ratio of glycerol to urea of $1-0.8$, catalyst loading of $2-4 \%$, stirrer rotation of 375,525 , and $700 \mathrm{rpm}$. Samples were taken every 15 minutes and analyzed of their residual glycerol concentration. The profile of the observed and calculated temperature and glycerol conversion for urea glycerolysis performed at temperature from $80{ }^{\circ} \mathrm{C}$ to $120^{\circ} \mathrm{C}$, ratio of glycerol to urea of 1 , catalyst loading of $2 \%$ and agitation speed of $375 \mathrm{rpm}$ are presented in Figure 4.

\subsubsection{The influence of agitation speed}

The effect of agitation speed was chosen at low, middle and high speeds. It was undertaken on 375,525 , and $700 \mathrm{rpm}$. For this variation, the catalyst loading was set at $2 \% \mathrm{w}$, the molar ratio of glycerol to urea of 1 and the temperature was operated from $80^{\circ} \mathrm{C}$ to $120^{\circ} \mathrm{C}$. As the agitation speed increased from 375 to $700 \mathrm{rpm}$, the observed glycerol conversions and predicted glycerol conversion were similar as shown in Figure 5. In addition, as the increasing agitation speed, the glycerol conversions for 300 minutes of reaction were $58.49,58.76$, and

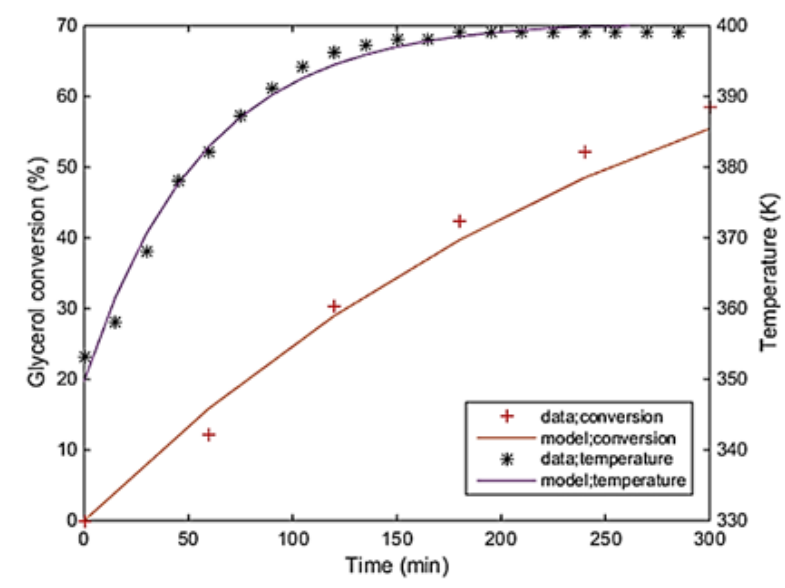

Figure 4. Comparison of the observed and calculated temperature and glycerol conversion for urea glycerolysis performed at temperature from $80^{\circ} \mathrm{C}$ to $120^{\circ} \mathrm{C}$, ratio of glycerol to urea of 1 , catalyst loading of $2 \%$ and agitation speed of $375 \mathrm{rpm}$.
$58.89 \%$ for agitation speed of 375,525 , and 700 rpm, respectively. It can be concluded that was no appreciable changes in glycerol conversion as increasing agitation speed.

Sulistyo et al. [23] investigated glycerol ketalization using Indion $225 \mathrm{Na}$ as a catalyst. They pointed out that there was no effect in glycerol conversion as increasing the agitation speed. Similar result was found when glycerol ketalization with acetaldehyde under stirring speed of 750 and $1250 \mathrm{rpm}$ [24]. Nanda et al. [25] investigated ketalization of glycerol under low stirring speeds and high stirring speed such as $400 \mathrm{rpm}$ and $1100 \mathrm{rpm}$ at $325 \mathrm{~K}$. They mentioned that increasing stirring speeds will drive to the same equilibrium yield of solketal. Meanwhile, Yadav \& Chandan [26] on the synthesis of glycerol carbonate by using hydrotalcite catalyst were studied in the range of 600-1000 rpm. Their results presented no significant change in reaction rate and glycerol conversion.

3.3.2 The influence of molar ratio of acetone to glycerol

The effect of glycerol to urea molar ratio was investigated on urea glycerolysis performed at catalyst concentration of $2 \%$, stirring speed of $375 \mathrm{rpm}$, temperature from $80{ }^{\circ} \mathrm{C}$ to $120^{\circ} \mathrm{C}$ and at varied of glycerol to urea ratio 1:1, 1:0.9, and 1: 0.8. Figure 6 shows the comparison of the observed and predicted glycerol conversion for urea glycerolysis performed at temperature from $80{ }^{\circ} \mathrm{C}$ to $120{ }^{\circ} \mathrm{C}$, catalyst loading of $2 \%$, agitation speed of 375-700 rpm at different ratio of glycerol to urea. It can be

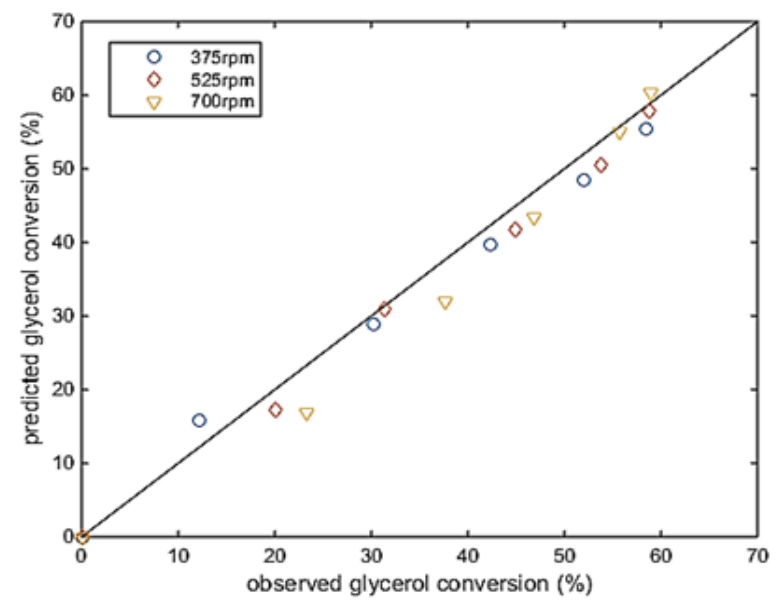

Figure 5. Comparison of the observed and predicted glycerol conversion for urea glycerolysis performed at temperature from $80^{\circ} \mathrm{C}$ to $120^{\circ} \mathrm{C}$, ratio of glycerol to urea of 1 , catalyst loading of $2 \%$ and agitation speed of 375-700 rpm. 
seen that the experimental data fit well to the model proposed. Figure 6 also shows that the stoichiometric molar ratio yielded the highest glycerol conversion of $58.49 \%$. Hammond et al. [27] also reported that the application of glycerol: urea ratio of $1: 1$ gave higher glycerol conversion than the one of glycerol: urea ratio of 1:0.5 in which the glycerol conversion were 57 and $40 \%$, respectively. In addition, Zhang and $\mathrm{He}$ [28] pointed out the excess of urea would cause a side reaction to form methyl carbamate. Urea glycerolysis using biosolids-based catalyst, Bartoli et al. [6] investigated by using equimolar of glycerol to urea molar ratio, the maximum glycerol conversion of $59.90 \%$ after 6 hours reaction. A carbonylation of glycerol with urea to form glycerol carbonate over $\mathrm{Zn} / \mathrm{MCM} 41$ catalyst on glycerol to urean molar ratio of 1:0.5 and 1:1, the glycerol conversion were of $44 \%$ and $84 \%$, respectively. The molar ratio of $1: 1$ (equimolar) resulted in the highest conversion of glycerol. It can be assumed this molar ratio was considered to be the most optimum.

\subsubsection{Effect of catalyst loading}

The effect of catalyst loading was investigated on urea glycerolysis performed at glycerol to urea ratio of $1: 1$, stirring speed of $375 \mathrm{rpm}$, temperature from $80^{\circ} \mathrm{C}$ to $120^{\circ} \mathrm{C}$ and at varied catalyst concentration of $2-4 \%$. The experimental data of the glycerol conversion also fit well with the proposed model (Figure 7).

Catalyst provides active sites at which reactants and products link through a specific reaction pathway which involves simultaneous at-

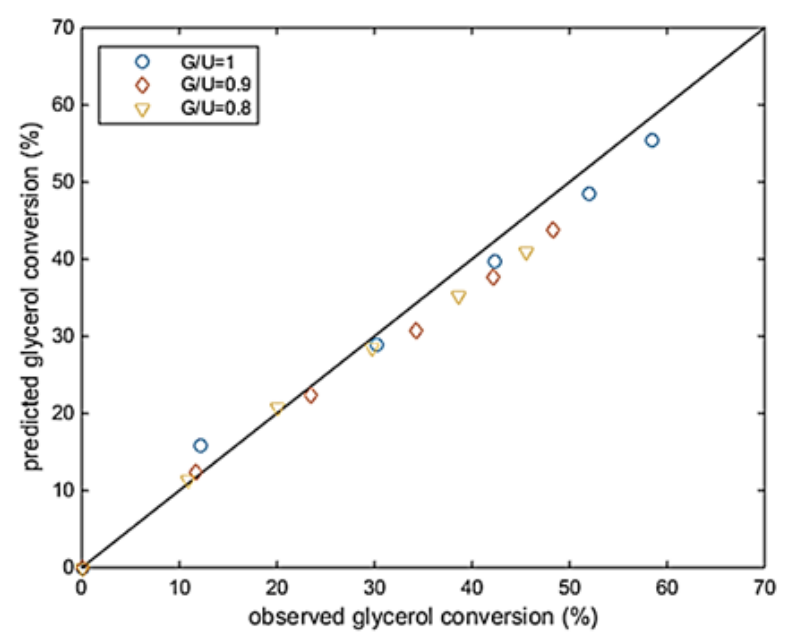

Figure 6. Comparison of the observed and predicted glycerol conversion for urea glycerolysis performed at temperature from $80{ }^{\circ} \mathrm{C}$ to 120 ${ }^{\circ} \mathrm{C}$, ratio of glycerol to urea of 1 , catalyst loading of $2 \%$ and agitation speed of $375-700 \mathrm{rpm}$. oms motion, collision and orientation. In urea glycerolysis, both acid and base sites are required [29]. Different catalysts in which having acidic sites, basic sites or acidic-basic sites were applied in glycerol carbonate synthesis through glycerolysis of urea $[6,12,29,30]$. The $\gamma$-zirconium phosphate, Zn/MCM-41, mixed oxides of $\mathrm{Al} / \mathrm{Mg}$ and $\mathrm{Al} / \mathrm{Li}$ hydrotalcites derived are examples of catalyst in which having both acid-basic sites and utilized in the urea glycerolysis processes [12,29,30]. $\mathrm{MgO}$ and $\mathrm{CaO}$ basic oxide are examples of basic sites catalyst for glycerol carbonate synthesis [30], while Amberlyst- 15 and biosolid based catalyst were two examples of catalyst with active sites [6,31]. Bartoli et al. [6] utilized biosolid-based catalyst, a solid residue obtained from thermal hydrolysis of municipal waste water by-product, in glycerol carbonate synthesis. The catalyst was reported contains a high concentration of metals and having a remarkable surface acidic sites concentration. Moreover, Amberlyst-15 is reported having acid capacity of 4.81 (eq. $\mathrm{H}^{+} \mathrm{kg}^{-1}$ ) [31]. The increase of acidic and basic sites as the result of the increase of catalyst loading will impact on the increase of the reaction rate. In case of the application of Amberlyst-15, the increase of catalyst loading impact on the increase of acid capacity as well as on rate of reaction in which represented by the increase of glycerol conversion.

\subsubsection{Collision factor and activation of energy}

Based on Arrhenius equation, reaction rate of catalytic reaction is faster than the one of thermally activated at the same temperature,

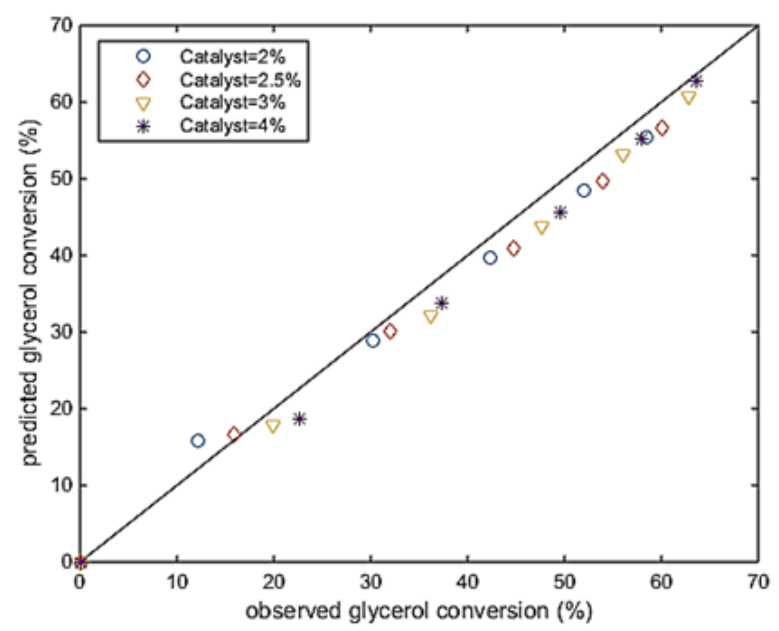

Figure 7. Comparison of the observed and predicted glycerol conversion for urea glycerolysis performed at temperature from $80^{\circ} \mathrm{C}$ to $120^{\circ} \mathrm{C}$, ratio of glycerol to urea of 1 , agitation speed of $375 \mathrm{rpm}$ and catalyst loading of $2-4 \%$. 
since it assumed that catalyst lowers the activation energy $(E)$ and escalates the collision factor [32]. In this work, the collision factor and activation of energy were examined from the experimental data of urea glycerolysis performed at different catalyst concentration (2$4 \%)$. The activation energy $(E)$ and the collision factor $\left(A_{r}\right)$ for all reaction performed at various catalyst concentration as well as activation energy of urea glycerolysis performed with different types of catalyst are tabulated on Table 2 . It was found that the value of collision factor of urea in the presence of $4 \%$ of Amberlyst- 15 was only $4.47 \%$ higher than the one of $2 \%$ of Amberlyst-15, while at the catalyst concentration higher than $2.5 \%$ the collision factor value were relatively constant. Hence, it can be conclude that the collision factors of urea glycerolysis reaction are identical. Furthermore, Table 2 also shows that the value of the activation energy from the application of catalyst concentration from $2 \%-4 \%$ were exactly the same since the difference were only $1.11 \%$. It was then fixed

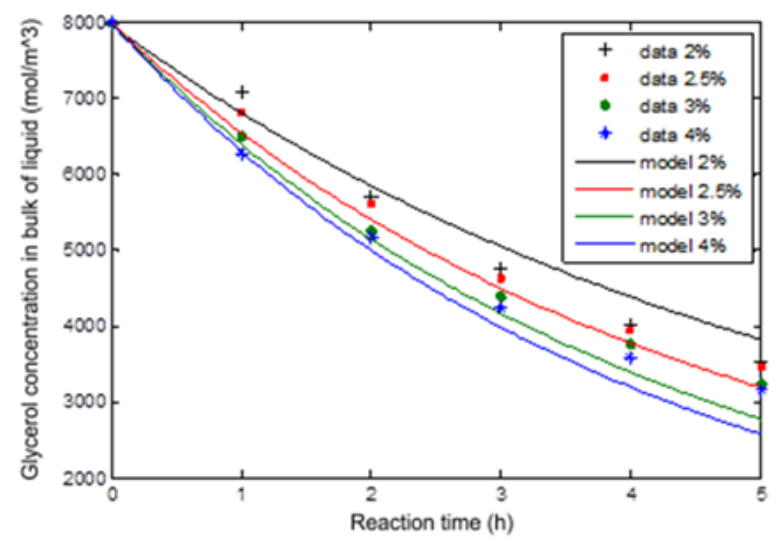

Figure 8. Glycerol concentration profile of urea glycerolysis. value of activation energy and collision factor in which comprised of average activation energy (145.58 kJ.mol-1) and average value of collision factor $\left(80.00\left(\left(\mathrm{~m}^{3}\right)^{2} / \mathrm{kg}\right.\right.$. mol.s) were applied.

Lower activation energies of urea glycerolysis were reported [15,29]. Moreover, higher activation energy of urea glycerolysis obtained from processes in which catalyzed by different catalyst were reported [33]. Kim et al. [33] compared the activity of Zn-imidazolium bromide immobilized in polystyrene (PS-( $\mathrm{Im})_{2} \mathrm{ZnBr}_{2}$ ), chitosan $\left(\mathrm{CH}-(\mathrm{Im})_{2} \mathrm{ZnBr}_{2}\right)$, and commercial silica $\left(\mathrm{CS}-(\mathrm{Im})_{2} \mathrm{ZnBr}_{2}\right)$. They reported the activation energy of 142.9, 163.0, and $166.7 \mathrm{~kJ} . \mathrm{mol}^{-1}$ for (PS-(Im) $\left.{ }_{2} \mathrm{ZnBr}_{2}\right),\left(\mathrm{CH}-(\mathrm{Im})_{2} \mathrm{ZnBr}_{2}\right)$, and (CS$\left.(\mathrm{Im})_{2} \mathrm{ZnBr}_{2}\right)$, respectively.

Furthermore, the kinetics modelling was then followed by recalculation of the kinetics parameters by applied the value of the average activation energy and the value of collision factor. The calculated and experimental data of glycerol concentration were illustrated on Figure 8 . The Figure 8 shows that the proposed model fit well to the experimental data of the glycerol concentration. The Amberlyts- 15 catalyst has a small effect to the collision factor and relatively does not give any impact on the activation energy. It can be assumed that catalyst do not change the reaction pathway but enhance and supply the active site for the reaction. The kinetics equation obtained, could be utilized to predict the glycerol conversion as time function, of various reaction temperature and catalyst concentration.

\subsection{Reactants Concentration in Catalyst Pores}

The simulation and validation of urea glycerolysis kinetics model was also give us the glycerol and urea concentration profile on the catalyst pores as time function and radial posi-

Table 2. Collision factor $\left(A_{\mathrm{r}}\right)$ and Activation energy $(E)$ of catalytic reaction of urea glycerolysis.

\begin{tabular}{lccccc}
\hline \multicolumn{1}{c}{ Catalyst } & $\begin{array}{c}\text { Glycerol : urea } \\
\text { ratio }\end{array}$ & $\begin{array}{c}\text { Catalyst } \\
\text { concentration } \\
(\%)\end{array}$ & $\begin{array}{c}A_{r} \times 10^{-10} \\
\left(\left(\mathrm{~m}^{3}\right)^{2} / \mathrm{kg} . \mathrm{mol} . \mathrm{s}\right)\end{array}$ & $\begin{array}{c}E \\
\left(\mathrm{~kJ} . \mathrm{mol}^{-1}\right)\end{array}$ & Reference \\
\hline Amberlyst 15 & $1: 1$ & 2 & 7.77 & 146.58 & This work \\
Amberlyst 15 & $1: 1$ & 2.5 & 8.03 & 145.62 & This work \\
Amberlyst 15 & $1: 1$ & 3 & 8.09 & 145.19 & This work \\
Amberlyst 15 & $1: 1$ & 4 & 8.12 & 144.95 & This work \\
Co3O4/ZnO & $1: 1$ & 1.5 & - & 31.89 & {$[15]$} \\
Zn supported catalyst & $1: 1$ & 10 & - & 39.82 & {$[29]$} \\
PS-(Im)2ZnBr2 & $1: 1$ & 5 & - & 142.9 & {$[33]$} \\
CH-(Im)2ZnBr2 & $1: 1$ & 5 & - & 163.0 & {$[33]$} \\
CS-(Im)2ZnBr2 & $1: 1$ & 5 & - & 166.7 & {$[33]$} \\
\hline
\end{tabular}


tion which are illustrated on Figures 9 and 10. It can be seen from Figure 9, that at the catalyst particle surface $(r=R k)$, the glycerol and urea concentration increase rapidly in the early stage of the reaction and then it were slowly decreasing. The glycerol and urea concentration at $r=0.75 R k$ are slowly increase due to the glycerol and urea just start diffuse to the inner part of the catalyst pores.

\section{Conclusion}

The kinetic studies show that mechanism proposed works well. The irreversibility of the second order reaction was proven and validated. The experimental data of glycerol conversion obtained from urea glycerolysis performed at varied agitation speed, ratio of glycerol to urea, and catalyst loading fit well to the proposed model. The activation energy of the urea glycerolysis was found to be $145.58 \mathrm{~kJ} . \mathrm{mol}^{-1}$ and the collision factor was $8.00 \times 10^{10}$ $\left(\mathrm{m}^{3}\right)^{2} \cdot \mathrm{kg}^{-1} \cdot \mathrm{mol}^{-1} \cdot \mathrm{s}^{-1}$. The simulation results also

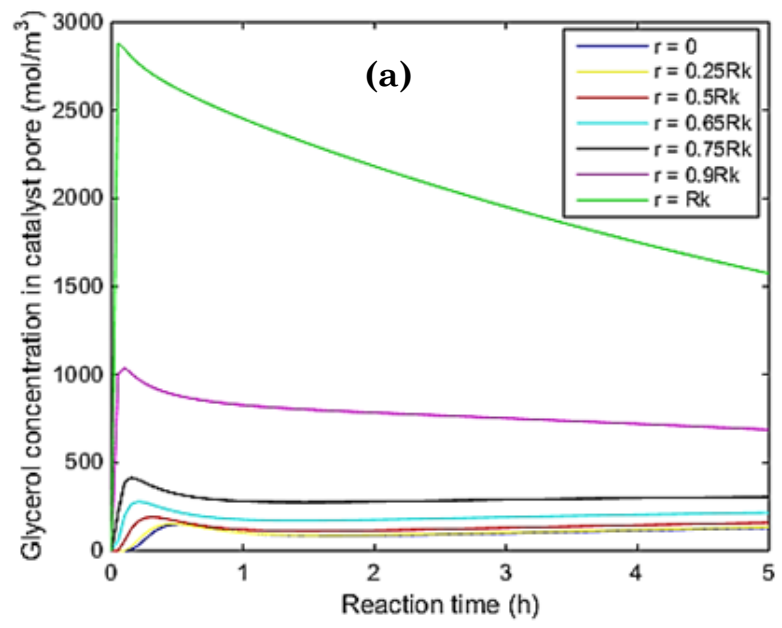

gave concentration profile of glycerol and urea inside the catalyst particle as time and position function.

\section{Acknowledgment}

The research team would like to thanks the Ministry of Research, Technology and Higher Education of Republic of Indonesia for funding this project through Penelitian Unggulan Perguruan Tinggi (PUPT) scheme year 2016, c o n t r a c t n u m b e r of 015/SP2H/LT/DRPM/II/2016.

\section{Nomenclatures}

$a=$ Constant in Equation 5

$a_{0}=$ Constant in Equation 6

$a_{1}=$ Constant in Equation 6

$A_{r}=$ Collision factor $\left(\left(\mathrm{m}^{3}\right)^{2} \cdot \mathrm{kg}^{-1} \cdot \mathrm{mol}^{-1} \cdot \mathrm{s}^{-1}\right)$

$b=$ Constant in Equation 5

$c \quad=$ Constant in Equation 5

$C_{A 0}=$ Initial concentration of glycerol $\left(\mathrm{mol} . \mathrm{m}^{-3}\right)$

Figure 9. Concentration profile of (a) glycerol and (b) urea on the catalyst pores as time function.
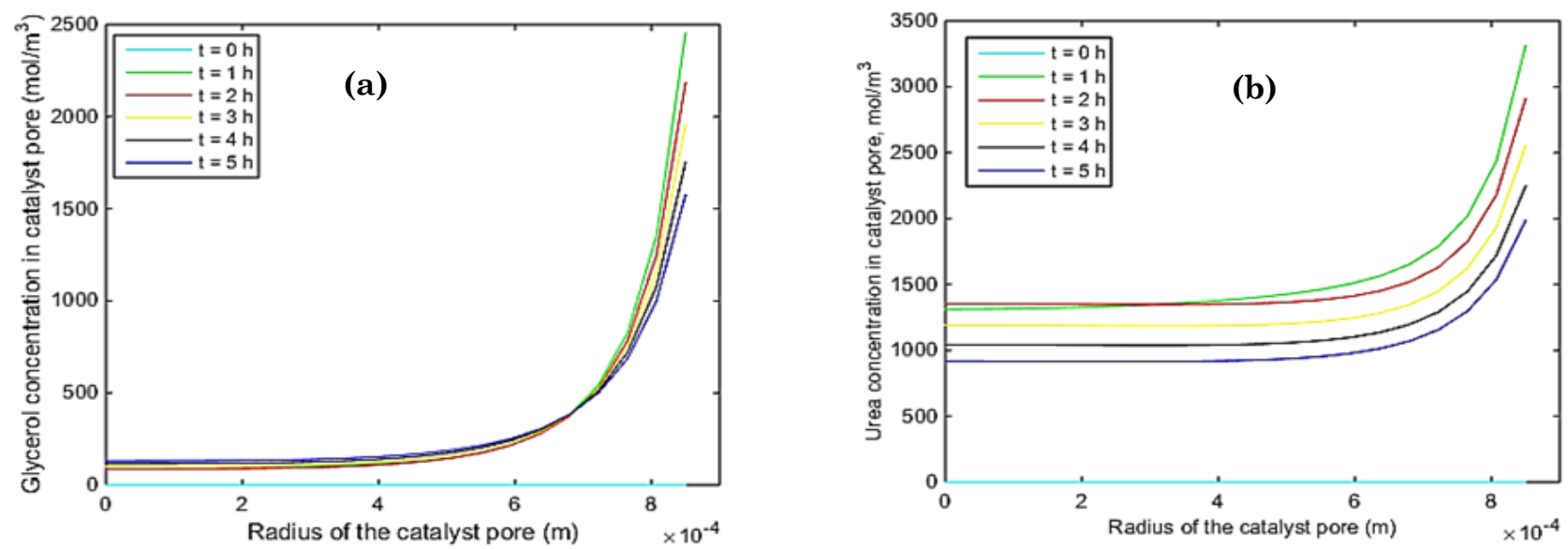

Figure 10. Glycerol and urea concentration profile on the catalyst pores in radial position. 
$C_{A L}=$ Concentration of glycerol in bulk fluid $\left(\mathrm{mol} . \mathrm{m}^{-3}\right)$

$C_{A}^{\prime}=$ Concentration of glycerol in pore of catalyts $\left(\mathrm{mol} . \mathrm{m}^{-3}\right)$

$C_{B 0}=$ Initial concentration of urea $\left(\mathrm{mol} . \mathrm{m}^{-3}\right)$

$C_{B L}=$ Concentration of urea in bulk fluid $\left(\mathrm{mol} . \mathrm{m}^{-3}\right)$

$C_{B}^{\prime}=$ Concentration of urea in pore of catalyst $\left(\mathrm{mol} . \mathrm{m}^{-3}\right)$

$D_{A B}=$ Molecular diffusivity $\left(\mathrm{m}^{2} \cdot \mathrm{s}^{-1}\right)$

$D_{e}=$ Effective diffusivity $\left(\mathrm{m}^{2} \cdot \mathrm{s}^{-1}\right)$

$D_{e A}=$ Effective diffusivity of glycerol $\left(\mathrm{m}^{2} . \mathrm{s}^{-1}\right)$

$D_{e B}=$ Effective diffusivity of urea $\left(\mathrm{m}^{2} . \mathrm{s}^{-1}\right)$

$E=$ Activation energy (kJ.mol-1)

$k_{C A}=$ Mass transfer coefficient of glycerol $\left(\mathrm{m} . \mathrm{s}^{-1}\right)$

$M_{B}=$ Molecular weight solvent, $\mathrm{kg} \cdot \mathrm{kmol}^{-1}$

$N_{k}=$ Number of catalyst

$R_{k}=$ Radius of catalyst particle (m)

$S h=$ Sherwood number

$t \quad=$ Time (s)

$T=$ Temperature $\left({ }^{\circ} \mathrm{C}\right)$

$V=$ Volume $\left(\mathrm{m}^{3}\right)$

$v_{A}=$ Solute molar volume at normal boiling point, $\mathrm{m}^{3} \mathrm{kmol}^{-1}$

$x=$ Glycerol conversion

$\phi_{p} \quad=$ Catalyst porosity

$\rho_{K} \quad=$ Catalyst density $\left(\mathrm{kg} \cdot \mathrm{m}^{-3}\right)$

$\mu \quad=$ Solution viscosity, $\mathrm{kg} \cdot \mathrm{m}^{-1} \cdot \mathrm{s}^{-1}$

$\sigma=$ Constriction factor

$\tau=$ Tortuosity

$\Phi_{p}=$ Catalyst porosity

$\varphi=$ Assoviation factor for solvent

\section{References}

[1] Kong, P.S., Kheireddine, M., Mohd, W., Wan, A. (2016). Conversion of crude and pure glycerol into derivatives: A feasibility evaluation. Renewable and Sustainable Energy Reviews, 63, 533-555, doi: 10.1016/j.rser.2016.05.054

[2] Galadima, A., Muraza, O. (2020). Waste materials for production of biodiesel catalysts: Technological status and prospects. Journal of Cleaner Production, 262, 121358, doi: 10.1016/j.jclepro.2020.121358

[3] Fernandes, G.P., Yadav, G.D. (2017). Selective glycerolysis of urea to glycerol carbonate using combustion synthesized magnesium oxide. Catalysis Today, 309, 153-160, doi: 10.1016/j.cattod.2017.08.021

[4] Slamet, S., Kusrini, E. (2015). Photocatalytic Hydrogen Production from Glycerol-water over Metal Loaded and Non-metal Doped Titanium Oxide. International Journal of Technology, 4, $520-532, \quad$ do i : 10.14716/ijtech.v6i4.2176
[5] Nomanbhay, S., Ong, M.Y., Chew, K.W., Show, P., Lam, M.K., Chen, W. (2020). Organic Carbonate Production Utilizing Crude Glycerol Derived as By-Product of Biodiesel Production: A Review. Energies, 13(6), 1483, doi: 10.3390/en13061483

[6] Bartoli, M., Zhu, C., Chae, M., Bressler, D.C. (2018). Value-Added Products from Urea Glycerolysis Using a Heterogeneous Biosolids-Based Catalyst. Catalysts, 8(9), 373, doi: 10.3390/catal8090373

[7] Sulistyo, H., Huda, E.N., Utami, T.S., Sediawan, W.B., Rahayu, S.S., Azis, M.M. (2020). Solketal production by glycerol acetalization using amberlyst -15 catalyst. ASEAN Journal of Chemical Engineering. 20(1), 67-76, doi: 10.22146/ajche.52455

[8] Zafar, M., Oman, S., Kumar, S., Kumar, S., Agrawal, J. Dhiman, A.K. (2014). Valorization of Glycerol into Polyhydroxyalkanoates by Sludge Isolated Bacillus sp . RER002 : Experimental and Modeling Studies. Chemical Product and Process Modeling, 9(2), 117131, doi: 10.1515/cppm-2014-001

[9] Climent, M.J., Corma, A., De-Fruots, P., Iborra, S., Noy, M., Velty, A., Concepcion, P. (2010). Chemicals from biomass: Synthesis of glycerol carbonate by transesterification and carbonylation with urea with hydrocalcite catalysts. The role of acid-base pairs. Journal of Catalyst, 269, 140-149, doi: 10.1016/j.jcat.2009.11.001

[10] Sonnati, M.O., Amigoni, S., Darmanin, T., Choulet, O. (2013). Glycerol carbonate as a versatile building block for tomorrow: synthesis, reactivity, properties and applications. Green Chemistry, 15, 283-306, doi: 10.1039/c2gc36525a

[11] Pradhan, G., Sharma, Y.C. (2020). Studies on green synthesis of glycerol carbonate from waste cooking oil derived glycerol over an economically viable $\mathrm{NiMgOx}$ heterogeneous solid base catalyst. Journal of Cleaner Production, $264, \quad 121258, \quad$ d o i : 10.1016/j.jclepro.2020.121258

[12] Aresta, M., Dibenedetto, A., Nocito, F., Ferragina, C. (2009). Valorization of bio-glycerol : New catalytic materials for the synthesis of glycerol carbonate via glycerolysis of urea. Journal of Catalysis, 268(1), 106-114, doi: 10.1016/j.jcat.2009.09.008

[13] Teng, W.K., Ngoh, G.C., Yusoff, R., Aroua, M. K. (2014). A review on the performance of glycerol carbonate production via catalytic transesterification: Effects of influencing parameters. Energy Conversion and Management, $88, \quad 484-497, \quad \mathrm{do}$ i : 10.1016/j.enconman.2014.08.036

[14] Wang, D., Zhang, X., Cong, X., Liu, S., Zhou, D. (2018). Influence of $\mathrm{Zr}$ on the performance 
of $\mathrm{Mg}$-Al catalysts via hydrotalcite-like precursors for the synthesis of glycerol carbonate from urea and glycerol. Applied Catalysis A: General, $555, \quad 36-46, \quad \mathrm{doi}$ : 10.1016/j.apcata.2018.02.009

[15] Lertlukkanasuk, N., Phiyanalinmat, S., Kiatkittipong, W. (2013). Chemical Engineering and Processing: Process Intensification Reactive distillation for synthesis of glycerol carbonate via glycerolysis of urea. Chemical Engineering \& Processing: Process Intensification, $70, \quad 103-109, \quad \mathrm{~d}$ o i : 10.1016/j.cep.2013.05.001

[16] Sulistyo, H., Sabariyanto, Ridho, M.N., Azis, M.M. (2019). Kinetics Modeling of Glycerol Carbonate Synthesis from Glycerol and Urea over Amberlyst-15 Catalyst. Indonesian Journal of Chemistry, 19(4), 1066-1073, doi: 10.22146/ijc. 42879

[17] Qing, Y., Lu, H., Liu, Y., Liu, C., Liang, B., Jiang, W. (2018). Production of glycerol carbonate using crude glycerol from biodiesel production with DBU as a catalyst. Chinese Journal of Chemical Engineering, 26(9), 1911919, doi: 10.1016/j.cjche.2018.01.010

[18] Fogler, H.S. (2005). Elements of Chemical Reaction Engineering. Fourth Edition. New Jersey: Prentice Hall.

[19] Amin, M., Alhalaweh, A., Velaga, S.P. (2011). Hansen solubility parameter as a tool to predict cocrystal formation. International Journal of Pharmaceutics, 407(1-2), 63-71, doi: 10.1016/j.ijpharm.2011.01.030

[20] Hansen, C. M. (2000). Hansen solubility parameters A User's Handbook (second edi). Boca Raton: CRC Press

[21] Kitak, T., Dumi A. (2015). Determination of Solubility Parameters of Ibuprofen and Ibuprofen Lysinate. Molecules, 20(12), 2154921568, doi: 10.3390/molecules201219777

[22] Li, J., Wang, T. (2011). Chemical equilibrium of glycerol carbonate synthesis from glycerol. The Journal of Chemical Thermodynamics, 43(5), 731-736, doi: 10.1016/j.jct.2010.12.01

[23] Sulistyo, H., Priadana, D.P., Fitriandini, Y.W., Ariyanto, T., Azis, M.M. (2020). Utilization of Glycerol by Ketalization Reactions with Acetone to Produce Solketal using Indion $225 \mathrm{Na}$ as Catalyst. International Journal of Technology, 11(1), 190-199, doi: 10.14716/ijtech.v11i1.3093

[24] Agirre, I., Güemez, M.B., Ugarte, A., Requies, J., Barrio, V.L., Cambra, J.F., Arias, P.L. (2013). Glycerol Acetals as Diesel Additives: Kinetic Study of the Reaction between Glycerol and Acetaldehyde. Fuel Processing Technolo gy, $116, \quad 182-188, \quad \mathrm{~d}$ o i : 10.1016/j.fuproc.2013.05.014
[25] Nanda, M.R., Yuan, Z., Qin, W., Ghaziaskar, H.S., Poirier, M.A., Xu, C. (2014). Thermodynamic and Kinetic Studies of a Catalytic Process to Convert Glycerol into Solketal as an Oxygenated Fuel Additive. Fuel, 117, 470477, doi: 10.1016/j.fuel.2013.09.066

[26] Yadav, G.D., Chandan, P.A. (2014). A Green Process for Glycerol Valorization to Glycerol Carbonate over Heterogeneous Hydrotalcite Catalyst. Catalysis Today, 237, 47-53, doi: 10.1016/j.cattod.2014.01.043

[27] Hammond, C., Lopez-Sanchez, J., Ab Rahim, M.H., Dimitratos, N., Jenkins, R.L., Carley, A.F., He, Q., Kiely, C.J., Knight, D.W., Hutchings, G.J. (2011). Synthesis of glycerol carbonate from glycerol and urea with goldb a s e d c a t a l y $\mathrm{s}$ t $\mathrm{s}$. Dalton Transactions, 40, 3927-3937, doi: 10.1039/C0DT01389G

[28] Zhang, J., He, D. (2014). Lanthanum-Based Mixed Oxides for The Synthesis of Glycerol Carbonate from Glycerol and Urea. Reaction Kinetics. Reaction Kinetics, Mechanisms and Catalysis, 113(2), 375-392, doi: 10.1007/s11144-014-0739-6

[29] Kondawar, S.E., Mane, R.B., Vasishta, A., More, S.B., Dhengale, S.D., Rode, C.V. (2017). Carbonylation of glycerol with urea to glycerol carbonate over supported $\mathrm{Zn}$ catalysts. Applied Petrochemical Research, 7(1), 41-53, doi: 10.1007/s13203-017-0177-2

[30] De Caro, P., Bandres, M., Urrutigoïty, M., Cecutti, C., Thiebaud-roux, S. (2019). Recent Progress in Synthesis of Glycerol Carbonate and Evaluation of Its Plasticizing Properties. Frontiers in Chemistry, 7, 308, doi: 10.3389/fchem.2019.00308

[31] Soto, R., Fité, C., Ramírez, E., Iborra, M., Tejero, J. (2018). Catalytic activity dependence on morphological properties of acidic ionexchange resins for the simultaneous ETBE and TAEE liquid-phase synthesis. Reaction Chemistry \& Engineering, 3, 195-205, doi: 10.1039/C7RE00177K

[32] Kulczycki, A., Kajdas, C. (2013). A New Attempt to Better Understand Arrehnius Equation and Its Activation Energy, In: Tribology in Engineering. Intech: 47-62. doi: $10.5772 / 54503$

[33] Kim, D., Kim, M., Roshith, K., Kim, M., Kwak, J., Park, D. (2014). Comparative catalytic activity of supported $\mathrm{ZnBr} 2$-containing ionic liquid catalysts for preparation of glycerol carbonate by glycerolysis of urea. Korean Journal of Chemical Engineering, 31(6), 972980, doi: 10.1007/s11814-013-0296-0 